\title{
Н.А. Беляева*
}

\section{ТАМОЖЕННЫЕ УЧРЕЖДЕНИЯ ПРИАМУРЬЯ В 1917 Г.: ОБЩЕСТВЕННАЯ ЖИЗНЬ И ПРОФЕССИОНАЛЬНАЯ ДЕЯТЕЛЬНОСТЬ}

\begin{abstract}
На основе архивных документов в статье рассматривается внутренняя жизнь таможенных учреждений Приамурья, уделяется внимание противоречиям между профессиональной и общественной стороной жизни работников таможни. Автор анализирует усилия департамента таможенных сборов, таможенных инспекторов и управляющих таможнями, направленные на борьбу с падением служебной дисциплины, преодоление раскола, сохранение авторитета таможенной службы в условиях революционного кризиса.
\end{abstract}

Ключевые слова: Приамурье, революционный кризис, таможенные учреждения, общественная жизнь, профсоюзы

The customs offices of Priamurye in 1917: public and professional life. NATALIA A. BELYAEVA (Vladivostok Branch of the Far Eastern Law Institute of the Ministry of Internal Affairs)

Based on archival documents, the article deals with the internal life of customs offices of Priamursky region, focusing on the contradictions between the professional and public sides of the life of customs employees. The author analyzes the efforts of the customs fees department, customs inspectors and customs administrators aimed at combating the violations of labour discipline and maintaining the authority of the customs service in the conditions of the revolutionary crisis.

Keywords: Priamurye, revolutionary crisis, customs offices, social life, trade unions

История таможенного дела в начале нынешнего века все более превращается в самостоятельное научное направление. В контексте экономической истории активно изучается тарифная политика [3], с точки зрения истории права - правовое регулирования таможенной деятельности $[2 ; 6]$; с точки зрения истории государства - таможня как один из институтов государства [4]. Все эти проблемы раскрываются на общероссийском и региональном материале и хронологически охватывают весь период существования российского государства. Наименее изученной на сегодняшний день остается история таможенных учреждений и таможенной деятельности периода революции и гражданской войны.

Отдельные сюжеты этой многогранной темы отражены в исследованиях финансовой политики белых правительств [10], истории борьбы с контрабандой [7; 9]. Некоторые аспекты истории таможенной службы освещались в отечественной историографии с точки зрения становления таможенной системы советского государства [8]. К сожалению, можно назвать лишь несколько современных публикаций, в которых рассматривается собственно функциони-

\footnotetext{
* БЕЛЯЕВА Наталья Анатольевна, профессор кафедры гуманитарных дисциплин Владивостокского филиала Дальневосточного юридического института МВД России.

E-mail: minava204@rambler.ru

(C) Беляева Н.А., 2017
} 
рование и положение таможенных учреждений в условиях гражданской войны $[1 ; 5]$.

Данная статья посвящена истории таможенных учреждений Приамурского края в 1917 г. При этом особое внимание уделено новым явлениям в жизни строго централизованного и бюрократически организованного таможенного ведомства, которые проявили себя в буквальном смысле с первых дней существования нового республиканского государства.

Исследование выполнено на основе архивных документов из фондов Российского государственного исторического архива Дальнего Востока: Хабаровского и Владивостокского таможенных участков, Владивостокской, Благовещенской и Хабаровской таможен. Часть документов извлечена из фонда Приамурского таможенного округа. Несмотря на то, что округ еще в 1912 г. прекратил свое существование, уступив место таможенным участкам как органам местного таможенного управления, в фонде сохранились некоторые документы, относящиеся к событиям 1917-1918 гг.

Большинство выявленных документов относится к таможенному делопроизводству: циркуляры департамента таможенных сборов и участковых таможенных инспекторов, распоряжения и приказы управляющих таможнями, рапорты таможенных чиновников, протоколы собраний и съездов местных отделов Всероссийского союза таможенных служащих. Все они позволяют увидеть новые явления в жизни таможенных учреждений, показать процесс преодоления противоречий между задачами таможни как государственного института и общественной активностью отдельных членов «таможенной семьи».

К началу революционных событий таможенные учреждения на территории Приамурья (таможни 2-го класса, таможенные заставы и посты) входили в состав Хабаровского и Владивостокского таможенных участков и подчинялись таможенным инспекторам. Таможни 1-го класса (Владивостокская и Николаевская-на-Амуре), находились в ведении департамента таможенных сборов и подчинялись участковым инспекторам лишь в инспекционном отношении. В годы Первой мировой войны приамурские таможни продемонстрировали способность работать в экстремальных условиях. Речь идет прежде всего о Владивостокской таможне, на плечи которой легло обеспечение бесперебойной работы Владивостокского порта.

В первые месяцы становления новой республиканской государственности таможенное ве- домство пыталось приспособиться к изменившимся условиям, чтобы не допустить хаоса на границе и перебоев в пропуске грузов. Многие направления деятельности таможенных учреждений сложились еще в период мировой войны: запреты и ограничения на ввоз отдельных категорий товаров, в первую очередь товаров воюющих с Россией государств; льготные условия пропуска грузов военного назначения; распространение преференций на торговлю новых государств, присоединившихся к Антанте. Все эти направления отражены в распоряжениях Временного правительства, министра финансов Временного правительства, циркулярах и распоряжениях департамента таможенных сборов [11]. Они касались исключительно профессиональной сферы, которая оказалась в прямой зависимости от общественной жизни, появившейся в таможенных учреждениях с первых дней новой эпохи.

Следует заметить, что многие шаги департамента таможенных сборов носили упреждающий характер. Еще 28 февраля 1917 г. на заседании временного комитета членов Государственной думы были назначены комиссарами по Министерству финансов И.В. Титов и В.А. Виноградов. Телеграфируя об этом во Владивосток и Хабаровск директор департамента С.А. Гринвальд и вновь назначенные комиссары просили «всех членов ведомства незамедлительно возобновить текущую работу в учреждениях Министерства финансов» (Российский государственный исторический архив Дальнего Востока, далее - РГИА ДВ. Ф. 25. Оп. 1. Д. 411. Л. 44).

Руководители таможенных учреждений - таможенные инспекторы и управляющие таможнями - с пониманием отреагировали на призыв руководства. Уже 6 марта в приказе по Владивостокской таможне управляющий И.К. Ковалевский призывал чиновников отнестись с доверием к новому правительству и «приложить все старания как к сохранению общего порядка ..., так и к исполнению священного долга перед родиной в смысле спокойного и энергичного продолжения каждым возложенных на него служебных обязанностей, памятуя, что наша таможня призвана служить на оборону государства» (РГИА ДВ. Ф. 25. Оп. 1. Д. 411. Л. 44 об.).

7 марта таможенный инспектор Н.Н Котлов посетил Хабаровский комитет общественной безопасности (КОБ) и от имени чинов вверенного ему участка заявил о полном доверии лицам, стоящим «во главе нового строя», о своей 
солидарности «с устанавливаемым порядком и полной готовности приложить все силы к службе на пользу и благо дорогой Родины» (РГИА ДВ. Ф. 1251. Оп. 1. Д. 22. Л. 26).

Подавляющее большинство таможенных чиновников также положительно восприняли рождение республиканской власти. Однако изменение политических условий не могло не сказаться на морально-психологической обстановке в таможенной среде. Первая проблема, которая отчетливо обозначилась в условиях революции, - падение дисциплины. Уже 11 марта 1917 г. Хабаровский таможенный инспектор направил всем подведомственным учреждениям циркуляр «О новых условиях работы». Наряду с обоснованием отношения к новой власти, письмо содержит обращение к определенной части сотрудников, которых инспектор призывает проникнуться пониманием важности в данный момент «нашей службы» для нашего отечества и «с полным доверием к старшим» (выделено мной - прим. авт.) исполнять свои обязанности, «ибо только при таких условиях возможна дружная успешная работа, и мы окажемся наиболее полезными слугами для нашей родины» (РГИА ДВ. Ф. 1251. Оп. 1. Д. 22. Л. 26-26об.). Можно было бы не акцентировать внимание на этом фрагменте, если бы через две недели, 25 марта 1917 г., инспектор не обратился со специальным посланием к таможенным досмотрщикам Хабаровского участка.

Поводом для письма стали участившиеся случаи неповиновения досмотрщиков «законным требованиям управляющего». Инспектор реагировал на появление первых признаков разрушения традиционных для таможенного ведомства отношений старших и младших служащих, выразившееся в нарушении служебной дисциплины и субординации. Из текста письма следует, что в таможенных учреждениях Хабаровского участка появились некие «темные личности», которые стараются «вооружить» младших служащих «против начальствующих лиц» (РГИА ДВ. Ф. 1251. Оп. 1. Д. 22. Л. 27). Подчеркивая, что нарушители дисциплины должны немедленно увольняться, инспектор на первый раз ограничился переводом «зачинщиков смуты» на другие таможенные посты, уволив лишь двух, мотивируя это нежеланием «омрачать светлые дни провозглашения свободы и гражданского равенства на нашей дорогой Родине и приняв во внимание принесенное им своим непосредственным начальникам извинение» (РГИА ДВ. Ф. 1251. Оп. 1. Д. 22. Л. 27).
Следует заметить, что состав таможенных досмотрщиков в годы Первой мировой войны претерпел серьезные изменения: многие были призваны из запаса в действующую армию, а освободившиеся вакансии занимались людьми случайными, не знавшими ни особенностей службы, ни тем более регламентирующих ее документов. Понятно, что малообразованные, имеющие временную работу, в условиях усилившегося давления, новые сотрудники таможенных учреждений были подвержены разным влияниям и весьма своеобразно понимали провозглашенную свободу. На этом обстоятельстве в обращении делается особый акцент: «Свобода, досмотрщики, не одно и то же, что произвол. Быть свободным гражданином, это не значит, что каждый может делать все, что ему вздумается. И свободное государство управляется на основании законов, соблюдение которых требуется несравненно строже, чем в государства несвободных. ...Вникните в это и не слушайте тех, которые стараются вооружить вас против начальствующих лиц... Воздержите ваших товарищей от нарушения дисциплины и не присваивайте себе прав, которые вам не даны законом, чтобы не подорвать к себе доверия в смысле разумного понимания вами свободы» (РГИА ДВ. Ф. 1251. Оп. 1. Д. 22. Л. 27).

На основании этого и других документов можно представить всю сложность процессов, которые «запускаются» внутри государственных учреждений - с одной стороны их демократизация, разрушение бюрократической иерархии, допущение элементов общественного контроля в деятельности таких «строго бюрократических» учреждений, как таможенные, с другой - вмешательство в управление, давление на чиновников, превращавшееся подчас в фактическое сведение счетов с «бывшими».

Наиболее ярко эти процессы проявились в Благовещенской таможне, коллектив которой в течение первой половины марта 1917 г. заседал почти ежедневно. Первое собрание, на котором были выбраны представители досмотрщиков для защиты их интересов «перед высшим начальством», состоялось 6 марта 1917 г. (РГИА ДВ. Ф. 1306. Оп. 2. Д. 543. Л. 2). Стремясь не упустить контроль над ситуацией, управляющий таможней В.А. Орликов на собрании 8 марта поставил вопрос о доверии себе и получил поддержку 109 чел. из 115 присутствовавших. Выразив доверие управляющему, собрание одновременно признало «нежелательным сочленом корпорации служащих Благове- 
щенской таможни» пакгаузного и корабельного смотрителя А.П. Цытовича, отличавшегося, по мнению большинства, бестактными и грубым отношением не только к сослуживцам, но и к горожанам. Собрание потребовало от управляющего уволить чиновника. В «сгустившейся атмосфере», как отмечал позже В.А. Орликов, он был вынужден уступить, хотя считал такое решение результатом «свободы страстей» - вопрос в отношении прослужившего 25 лет в ведомстве чиновника не мог быть решен без объективного учета всех обстоятельств (РГИА ДВ. Ф. 1306. Оп. 2. Д. 543. Л. 6-6об.).

Не менее сложной была обстановка в учреждениях Владивостокского инспекторства. В июне 1917 г. комитет служащих Пограничной таможни фактически парализовал ее работу. Конфликт вышел на уровень департамента таможенных сборов, который разъяснил противоборствующим сторонам, что «вся ответственность за правильное течение дел в таможне лежит на управляющем», а потому ни комитеты, ни отдельные служащие или группы служащих не могут вмешиваться «в дела управления таможней», претендовать на контроль за деятельностью управляющего, «входить в обсуждение правильности или целесообразности его распоряжений», не касающихся непосредственно самих служащих или препятствовать их исполнению. Равным образом право назначения, перемещения и увольнения со службы действующими законами также не предоставлено ни самим служащим, ни их выборным органам» (РГИА ДВ. Ф. 25. Оп. 1. Д. 408. Л. 200).

Департамент всерьез беспокоило развитие событий в таможенных учреждениях, в которых отношения досмотрщиков (младших служащих) и чиновников (старших служащих) приобретали откровенно конфронтационные формы. Увольнение квалифицированных сотрудников, а то и руководителей таможенных учреждений по требованию общих собраний и повсеместно возникавших комитетов могло иметь необратимые последствия для таможенной деятельности. Выход из ситуации виделся в достижении компромиссов, а в дальнейшем - в создании организационных основ для решения кадровых вопросов в принципиально новых условиях.

Департамент предпринял в этом направлении некоторые шаги. Еще 22 апреля 1917 г. циркулярным порядком до таможенных инспекторов и управляющих первоклассными таможнями было доведено решение Министра финансов об образовании в таможнях особых смешанных комиссий из заинтересованных сторон «для разрешения вопросов, возникающих на служебной почве между служащими». Вопрос о составе комиссий, ввиду сложности и многообразия возникающих вопросов, был передан на усмотрение местных учреждений. Форма, в которую «выльется решение комиссии», должна была устанавливаться ею самой. В случае, если дело требовало вмешательства высшего начальства, составлялся особый журнал (протокол) с изложением конкретных обстоятельств дела и приложением письменных объяснений заинтересованных сторон, «если те пожелали дать такие объяснения» (РГИА ДВ. Ф. 25. Оп. 1. Д. 408. Л. 48). Такой порядок был рекомендован для всех таможен и управлений таможенных инспекторов.

Циркуляр департамента таможенных сборов был получен во Владивостоке и Хабаровске только в середине мая. К этому времени Н.Н. Котлов самостоятельно принял решение о создании в Хабаровском участке таможенного комитета из 6 человек выборных (поровну) от чиновников и досмотрщиков. Для того, чтобы обеспечить равное представительство от всех досмотрщиков, была разработана сложная система двухступенчатых выборов при тайном голосовании (баллотировке), в результате от 415 досмотрщиков, несших службу в таможенных учреждениях (за исключением Камчатки и Сахалина), должны быть избраны 3 действительных члена и 3 кандидата. Все они прикомандировывались к Хабаровской таможне, где и несли обычную службу досмотрщиков в свободное от занятий в таможенном комитете время [13, с. 87-88]. Выборы чиновников, которых было существенно меньше, осуществлялись путем направления конвертов с именами кандидатов. Члены и кандидаты определялись большинством голосов. Таможенный инспектор, его помощники, управляющий Хабаровской таможней не могли быть в числе избранных (РГИА ДВ. Ф. 1305. Оп. 1. Д. 134. Л. 200).

Выборы в комитет таможенных служащих прошли 20 июня 1917 г. Сам инспектор возлагал на коллегиальный орган большие надежды в части разъяснения сути произошедших событий. Главную причину конфликтов в таможенной среде он видел как раз в непонимании сути происходящего менее образованной частью служащих и важнейшую задачу чиновников именно в такой разъяснительной работе.

Однако уже к лету 1917 г. невозможность урегулирования конфликтов на уровне отдель- 
ных таможенных учреждений стала очевидной. В таможенной среде все более распространялась идея создания общероссийской профессиональной организации. Ее активно поддерживали и рядовые служащие, и управленческие структуры. Первые видели в создании профсоюза единственный способ защиты социальных прав и экономических интересов, преодоления оставшейся от «старого строя» жесткой иерархии. Вторые восприняли идею профсоюзного единения как способ выстроить новые отношения доверия и одновременно привлечь наиболее активных «общественников» к решению целого ряда важных социальных проблем таможенного ведомства, отвлекая их от вмешательства в профессиональную сферу. Таким образом, предполагалось четко отделить общественную жизнь, где возможность инициативы регламентировалась бы уставом союза, от профессиональной деятельности, осуществлявшейся на основе продолжавшего действовать таможенного устава и правительственных постановлений.

Идея создания профессионального союза таможенных служащих была поддержана в департаменте таможенных сборов и Министерстве финансов Временного правительства. Информируя об этом руководителей таможенных учреждений 22 июля 1917 г., директор департамента С.А. Гринвальд признавал созыв Всероссийского съезда таможенных служащих «весьма желательным», поскольку его программа касалась не только профессионального объединения, но и других важных для службы «текущих вопросов». Инспекторам и управляющим таможнями 1-го класса предлагалось оказать всяческое содействие в выборах делегатов на Всероссийский съезд, не нарушая при этом «нормального хода текущей служебной работы» (РГИА ДВ. Ф. 25. Оп. 1. Д. 408. Л. 137).

В таможенных учреждениях Приамурья нашла полную поддержку инициатива служащих Московской таможни по созданию Всероссийского союза таможенных служащих. Однако развитие профессионального движения в таможенных учреждениях на дальневосточной окраине проходило независимо от скорости и интенсивности этого процесса в центре. Первая профессиональная таможенная организация возникла в Благовещенске - еще 17 марта 1917 г. здесь был избран исполнительный комитет союза служащих Благовещенской таможни [12, с. 98]. Цели и задачи организации были отражены в ее Уставе. Главная цель союза определялась как сплочение «на основах взаимопомощи, справед- ливости и уважения человеческой личности для удовлетворения и защиты профессиональных и экономических нужд служащих, а также для отстаивания гражданских их прав» [12, с. 91]. Через профессиональную организацию предполагалось решить целый ряд задач: добиваться улучшения материального положения прежде всего малообеспеченных (занимающих «низшие должности») членов союза; предоставления сотрудникам и семьям врачебной помощи «при минимальных затратах», а лучше бесплатной; решать жилищную проблему за счет предоставления казенных квартир не только чиновникам, но и досмотрщикам; обеспечить доступ к бесплатному образованию всех ступеней и создать возможности для самообразования через открытие при таможне библиотеки, организацию чтений и т.д.; разработать «пенсионный устав» с учетом местных особенностей; регулировать продолжительность рабочего дня; создать «примирительные камеры» (товарищеские суды) для разрешения возникающих меду членами союза недоразумений. Однако среди задач профсоюза были сформулированы и выходившие за пределы социальных вопросов. К ним относилась, например, «разработка вопросов, касающихся упорядочения таможенных обрядностей и служебных отправлений как внешней, так и внутренней службы», т.е. упрощение таможенных процедур; «разработка вопросов, касающихся чисто таможенного дела во всем его целом применительно к краевым условиям жизни» [12, с. 92]. Такое расширительное понимание компетенции таможенного союза можно рассматривать как предпосылку к тому хаосу, в котором окажется Благовещенская таможня в недалеком будущем. В июле 1918 г. исполнявший в отсутствие Н.Н. Котлова обязанности таможенного инспектора Н.А. Матушевский с тревогой отмечал: «В Благовещенской таможне хаос во всех частях. Управляется коллективом из трех чиновников, трех досмотрщиков. Занимаются больше политикой, интригами» (РГИА ДВ. Ф. 1304. Оп. 1. Д. 137. Л. 58). Ситуация грозила стать неуправляемой на фоне давления извне принятия съездом крестьян и казаков Амурской области решения о немедленном упразднении Благовещенской таможни и всех таможенных учреждений области с передачей охраны границы советам. Однако летом 1917 г. трудно было предположить, что события развернутся таким драматическим образом.

Профессиональные союзы приамурских таможен изначально позиционировали себя как 
часть общероссийской таможенной организации, активно сотрудничали с организационным бюро по созыву 1-го Всероссийского съезда таможенных служащих, участвовали в выборах делегатов на Первый съезд и непосредственно в его работе.

Состоявшийся в Петрограде в сентябре 1917 г. первый съезд Всероссийского союза таможенных служащих можно рассматривать как попытку сохранения «единства» таможенной семьи и ее профессиональной идентичности. Однако происшедшие вскоре октябрьские события, отношение к которым в таможенной среде было далеко не так однозначно, усилили наметившийся раскол, придав ему политическую окраску. На Дальнем Востоке эти процессы вылилась в увольнение целого ряда знаковых фигур под предлогом их несоответствия новым условиям. Как это ни парадоксально, но дезорганизация таможенной службы была остановлена начавшейся гражданской войной и интервенцией. В условиях политической нестабильности таможенные учреждения оказались едва ли не единственным государственным институтом, продолжавшим защищать «интересы казенного управления» даже после крушения самого государства.

\section{СПИСОК ЛИТЕРАТУРЫ}

1. Архирейский Д.В. Таможенные структуры Украины в период гражданской войны 19171921 гг. // Государство - экономика - политика: актуальные проблемы истории: сборник научных трудов Всероссийской научно-методической конференции. 11-13 мая 2010. СПб.: Издательство Политехнического университета, 2010. С. 6-10.

2. Балковая В.Н. Нормативное регулирование таможенного дела в первой четверти XIX в. // Таможенная политика России на Дальнем Востоке. 2017. № 2(79). С. 112-120.

3. Волков Д.В. Таможенное дело в России XIX века: опыт таможенно-тарифного регулирования // Известия РГПУ им. А.И. Герцена. 2007. №53. С. 67-71.

4. Волков Р.С. Институционализация таможенной службы // Вестник Челябинского государственного университета. 2009. № 33. С. 180-184.

5. Дейнеко С. Всеросійська спілка митних службовців у 1917 році // Вісник Харківського національного університету імені В.Н. Каразіна. Серія: Історія. 2014. Вип. 49. С. 57-68.

6. Котихина А.С. Нормативно-правовое регулирование организации и деятельности таможни в Советской России 1917-1928 гг. // Юридическая наука и практика: Вестник Нижегородской академии МВД России. 2011. № 1. С. 38-41.

7. Ляпустин С.Н., Беляева Н.А. Организация борьбы с контрабандой в условиях гражданской войны и интервенции на Дальнем Востоке. Владивосток: РИО Владивостокского филиала Российской таможенной академии, 2014.

8. Марков Л.Н. Очерки по истории таможенной службы. Иркутск: Изд-во Иркутского госуниверситета, 1987.

9. Попенко А.В. Опыт борьбы с контрабандой на Дальнем Востоке России (1884 - конец 20-х гг. ХХ в.). Хабаровск: Хабаровский пограничный институт ФСБ России, 2009.

10. Рынков В.М. Финансовая политика антибольшевистских правительств востока России (вторая половина 1918 г. - начало 1920 г.). Новосибирск, 2006.

11. Сборник узаконений и циркуляров по таможенной части за 1917 год. Петроград: Тип. Главного управления Пограничной охраны, 1918.

12. Таможня на Тихом океане: Документы и материалы. Вып. 1. Благовещенская таможня / сост. Н.А. Беляева, Н.А. Троицкая, Е.Д. Яворская. Владивосток: РИО ВФ РТА, 2002.

13. Таможня на Тихом океане: Документы и материалы. Вып. 2. Хабаровская таможня / сост. Н.А. Беляева, Н.А. Троицкая. Владивосток: ВФ PTA, 2004.

\section{REFERENCE}

1. Arkhireyskiy, D.V., 2010. Tamozhennye struktury Ukrainy $\mathrm{v}$ period grazhdanskoy voyny 1917-1921 gg. [The customs authorities of Ukraine during the Civil war, 1917-1921]. In: Gosudarstvoekonomika - politika: aktual'nye problemy istorii: sbornik nauchnykh trudov Vserossiyskoy nauchno-metodicheskoy konferentsii. 11-13 maya 2010. Sankt-Peterburg, pp. 6-10. (in Russ.)

2. Balkovaya, V.N., 2017. Normativnoye regulirovaniye tamozhennogo dela $\mathrm{V}$ pervoy chetverti XIX v. [Legal regulation of customs affairs in the first quarter of the XIXth century], Tamozhennaya politika Rossii na Dal'nem Vostoke, no. 2(79), pp. 112-120. (in Russ.)

3. Volkov, D.V., 2007. Tamozhennoye delo v Rossii XIX veka: opyt tamozhenno-tarifnogo regulirovaniya [Customs in nineteenth-century Russia: the experience of customs and tariff regulation], Izvestiya RGPU im. A.I. Gertsena, no. 53, pp. 67-71. (in Russ.)

4. Volkov, R.S., 2009. Institutsionalizatsiya tamozhennoy sluzhby [The institutionalization 
of the customs service], Vestnik Chelyabinskogo gosudarstvennogo universiteta, no. 33, pp. 180184. (in Russ.)

5. Deineko, S., 2014. Vserosiis'ka spilka mitnikh sluzhbovtsiv u 1917 rotsi [All-Russian union of customs officials in 1917], Visnik Kharkivs'kogo natsional'nogo universytetu imeni V.N. Karazina. Seriya: Istoriya, no. 49, pp. 57-68. (in Ukrainian)

6. Kotikhina, A.S., 2011. Normativnopravovoye regulirovaniye organizatsii i deyatel'nosti tamozhni v Sovetskoy Rossii 19171928 gg. [Legal regulation of organization and activities of customs in Soviet Russia, 19171928], Yuridicheskaya nauka i praktika: Vestnik Nizhegorodskoy akademii MVD Rossii, no. 1, pp. 38-41. (in Russ.)

7. Lyapustin, S.N. and Belyaeva, N.A., 2014. Organizatsiya bor'by s kontrabandoy v usloviyakh grazhdanskoy voyny i interventsii na Dal'nem Vostoke [Organization of fight against smuggling in the context of Civil war and intervention in the Russian Far East]. Vladivostok. (in Russ.)

8. Markov, L.N., 1987. Ocherki po istorii tamozhennoy sluzhby [Essays on the history of the customs service]. Irkutsk. (in Russ.)
9. Popenko, A.V., 2009. Opyt bor'by s kontrabandoy na Dal'nem Vostoke Rossii (1884 konets $20-\mathrm{kh}$ gg. $\mathrm{XX}$ v.) [The fight against smuggling in the Russian Far East (1884 - the end of the 1920s)]. Khabarovsk. (in Russ.)

10. Rynkov, V.M., 2006. Finansovaya politika antibol'shevistskikh pravitel'stv vostoka Rossii (vtoraya polovina 1918 - nachalo 1920 g.) [Financial policy of anti-Bolshevik governments of the Russian East (the second half of 1918 - the beginning of 1920)]. Novosibirsk. (in Russ.)

11. Sbornik uzakoneniy i tsirkulyarov po tamozhennoy chasti za 1917 god [A collection of laws and circulars on customs for 1917]. Petrograd, 1918. (in Russ.)

12. Tamozhnya na Tikhom okeane: Dokumenty i materialy. Vyp. 1. Blagoveshchenskaya tamozhnya [Customs service in the Pacific Russia. Documents and materials. Vol. 2. Blagoveshchensk customs]. Vladivostok, 2002. (in Russ.)

13. Tamozhnya na Tikhom okeane: Dokumenty i materialy. Vyp. 2. Khabarovskaya tamozhnya [Customs service in the Pacific Russia. Documents and materials. Vol. 2. Khabarovsk customs]. Vladivostok, 2004. (in Russ.)

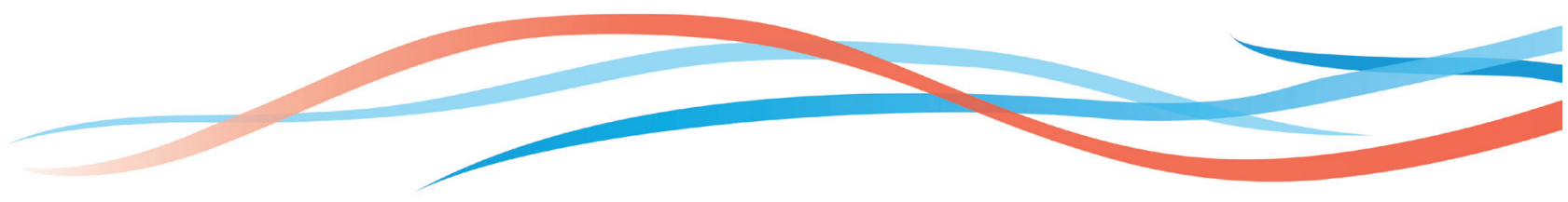

